\title{
XI. On the use of the galvanic battery in blasting
}

\section{Hamilton K.G. Morgan}

To cite this article: Hamilton K.G. Morgan (1839) XI. On the use of the galvanic battery in blasting, Philosophical Magazine Series 3, 15:93, 60-62, DOI: $10.1080 / 14786443908649822$

To link to this article: http://dx.doi.org/10.1080/14786443908649822

册 Published online: 01 Jun 2009.

Submit your article to this journal

Џ Article views: 2

Q View related articles $₫$ 
near Kissingen, the Adelheids quelle, near Heilbroun, and above all, the springs of Kreugnach, which have been found highly beneficial in scrophulous diseases when internally administered, their action being dependent entirely on the chlorides, iodides, and bromides they contain. Sea-water would afford similar advantages for bathing, and when evaporated to dryness, the residue might be kept in earthen vessels, and thus be conveyed to any distance; and as its constituents are very soluble, sea-water in perfection might be procured at any place. 'The evaporation of sea-water should be performed with care, and the ingredients kept by chemists. One great advantage would accrue from this method, viz. that sea-water could be had of any degree of concentration which the practitioner might deem necessary. At the baths of Kreugnach, for example, extraordinary effects have been produced when from 4.0 to 70 quarts of the mother liquor were added to the natural salt-water of that spring, and this mixture used for bathing.

German Spa, Brighton, June 1839.

XI. On the Use of the Galvanic Battery in Blasting. By Hamilton K. G. Morgan.

\section{To the Editors of the Philosophical Magazine and Journal.}

Gentlemen, Johnstone Castle, Wexford, May 24, 1839.

I BEG to trespass on your time by this letter on the use of 1 the galvanic battery, instead of the fuze in blasting.

The papers have given short descriptions of the experiments made at Chatham, but all the details were not given. I commenced my experiments on blocks of the old trees that were blown down by the late storm. I first prepared an igniting cartridge by joining two pieces of clean copper wire to the extremities of a steel wire taken from the scratch brush, such as is made use of by gun-makers; this steel wire is fastened to the copper wires by waxed silk; the length of steel wire to be deflagrated is one-fourth of an inch; a piece of very slight wood is spliced to both copper wires to protect the steel wire from any accident-it makes the whole strong and more convenient to be introduced intothe small cartridge, which is either a quill or a small paper tube. They are filled with fine powder, and made air-and water-tight, to prevent the powder from getting damp and rusting the steel wire; a second small piece of wood is then fastened to this small cartridge and the copper wires; one of the wires is bent over this piece of wood and brought up at an angle with the other up- 
right wire. This is my exploding cartridge : it cannot be easily put out of order. The wires of the cartridge have only to be made bright before they are fastened, by twisting them round the positive and negative wires of the battery. I always place the cartridge deep in the hole made to receive the powder, in oider that the pressure from the turnpeg may be taken off by the quantity of powder above it.

The wire I make use of is the common copper bell-wire. The battery is the old Wedgewood trough, with 4-inch plates, double coppers. I prevent the zinc plates from touching the copper by small pegs of wood passed through the four corners. Wooden troughs with moveable divisions were tried, but not with any good result. A wooden trough with the plates in a frame of wood with varnished paper between the copper was tried, but the porcelain trough far surpassed them. My first experiment was blasting single blocks; the effect was much better than when the fuze was used, in consequence of the clay being more firmly driven round the wires than it would be round the larger surface of the fuze. 2ndly, I selected two large blocks nearly in line; the first block was 43 feet from the battery; the second block 113 feet from the battery, and the blocks consequently were 70 feet from each other. On dipping the plates the explosions took place in quick succession; the battery consisted of 30 pairs of 4-inch plates. 3rdly, I wished to try the effect of a simultaneous explosion of two blasts on a very large block tirmly tied together by rivets. The positive wires of each cartridge were fastened to the positive connecting wire, and in like manner the negative wire. The effects of this simultaneous explosion were very good; the exciting liquor being weak, the connecting wires were shortened to 98 feet. 4th, 'To amuse some friends, I exploded some powder in one of the ponds, depth 10 feet; length of wire 210 feet ; 40 pairs of plates, with old exciting liquor :the experiment succeeded to the delight of all; a large eel was killed by the blow-up. I have no doubt but that wildfowl will yet be killed by means of shells placed at low water on the banks where they feed; and by means of long connecting wires, the shells can be made to explode simultaneously among the birds.

I find that 10 pairs of 4 -inch plates free from oxide and charged with the following exciting liquor-water, $6 \frac{1}{2}$ quarts; sulphuric acid of commerce, $4 \frac{1}{2}$ ounces; nitrous acid, $4 \frac{1}{4}$ ounces; will ignite powder with a wire 101 feet long. 20 pairs of plates ignited powder at the distance of 353 feet. I tried to repeat this experiment, but did not succeed, though the plates were 
only three times immersed in the acid, and only for about two seconds each time. I tried the same battery at 268 feet, and did not succeed. The plates were then well washed, and fresh exciting liquor made : the experiment again failed; the plates were quite inactive. The next day I tried the same plates and the same exciting liquor, and succeeded at 268 feet. From this it seems impossible to say how many pairs of plates would be required to produce uniform effects at long distances. I suspect that the zinc plates do not act equally in producing the electricity, which causes this variation.

I should have liked very much to have tried the conducting properties of different sized wires, but had not an opportunity of getting them here.

Not having seen any notice of this novel and safe method of blasting in your excellent journal, induced me to send you these few remarks.

$I$ believe I am the first in Ireland that applied the galvanic battery instead of the fuze in blasting.

I remain, Gentlemen, yours, \&c.

Hamilton K. G. Molgan.

XII. On the Equivalent of Carbon. By Mr. George Fownes.

Sir,

To R. Phillips, Esq. F.R.S. \& c.

HAVING read with great interest an extract from the "Journal de Pharmacie," in your Number for February, on the composition of naphthalin, by M. Dumas, and the probability, in his opinion, of the existence of an error in the commonly received combining number of carbon, $I$ beg to send you an account of some recent analyses of that substance, and also of three other compounds of hydrogen and carbon, made in the laboratory of the Middlesex Hospital Medical School: I must leave it to you to decide whether these experiments are of a proper kind to occupy a page of your Journal in the absence of more original and important matter.

The subject of the composition of naphthalin has engaged the attention of chemists ever since its discovery, and notwithstanding the care which has been bestowed on its analysis, the results differ more than ought to be expected from processes so accurate as those employed in the investigation. There is one circumstance, however, to be remarked in nearly all, namely, that the sum of the weights of the hydrogen and carbon obtained by experiment, always exceeds that of the sub- 